\title{
A (IN)DIFERENÇA ENTRE PRINCÍPIOS E REGRAS: REPENSANDO A TEORIA DOS PRINCÍPIOS COM AULIS AARNIO
}

Frederico Magalhães Costa ${ }^{1}$

\section{Resumo}

O presente artigo tem por objetivo questionar o dogma estabelecido pela teoria dos princípios de que as normas se distinguem em regras e princípios. Adota a metodologia jurídicocompreensiva para iniciar uma revisão bibliográfica e de análise de conteúdo das teses que enfrentam a problemática da normatividade dos princípios. A seguir, analisa as críticas à teoria da norma de Kelsen, ao modelo de aplicação normativa do Direito Nazista, relacionando-o com o modelo de princípios da Jurisprudência dos Valores. Depois, reflete sobre teses fracas e fortes da distinção entre princípios e regras e conclui, explicitando a compreensão de que não há distinção significativa entre tais normas, com fundamento na construção teórica do professor finlandês Aulis Aarnio.

Palavras-chave: teoria do direito; teoria da norma; teoria dos princípios; regras; princípios.

\section{THE (IN)DIFFERENCE BETWEEN PRINCIPLES AND RULES: RETHINKING THE PRINCIPLE'S THEORY WITH AULIS AARNIO}

\begin{abstract}
The present paper intends to question the dogma instituted by the principle's theory that norms are distinguished in rules and principles. By the judicial-comprehensive method and by the bibliographic approach this paper stars with a review of some thesis that face the problem of principle normativity. Then analyses the main review of Kelsen's norm theory and the Nazis normative application standard relating it with Value Jurisprudence's principle theory. After that, considers strong and weak distinctions between principles and rules and concludes showing the understanding that there is no meaningful distinction between these norms, supported in the theory of the finnish professor Aulis Aarnio.
\end{abstract}

Keywords: law theory; norm's theory; principles' theory; rules; principles.

\section{INTRODUÇÃO}

A distinção entre regras e princípios se notabilizou após a construção teórica do filósofo americano Ronald Dworkin, seguida das contribuições do constitucionalista alemão Robert Alexy. Trata-se de concepção que se tornou influente para além do espaço teutoamericano e foi disseminada como bandeira de enfrentamento contra as teses (neo)positivistas

\footnotetext{
${ }_{1}^{1}$ Professor da UNEB, mestrando em Direito pela UFBA, especialista em Filosofia e TEoria do Direito pela PUC/MG e em Direito Civil pela Faculdade Baiana de Direito/Juspodivm. E-mail: fredcosta88@gmail.com
} 
de Kelsen (2009) e de Hart (2009) sobre a incomunicabilidade entre direito e moral ao defender a ideia de que o Direito não se esgota nos enunciados normativos positivados.

Ocorre que a pretensão de regresso dos standards éticos e cânones morais como balizas das teorias da norma e da decisão que ampliaram o conceito de norma, passando a abarcar também os princípios, trouxe consigo a franca liberdade de atribuição de sentidos às pautas valorativas de conduta e o consequente descionismo, diminuindo, dessa forma, a importância do padrão regulatório das regras.

Esta alteração de paradigma no âmbito da compreensão da norma de direito, mais especificamente, da teoria da norma jurídica, trouxe consequências importantes sobre muitos aspectos para toda a dogmática jurídica e, no âmbito da hermenêutica jurídica, acabou por evidenciar, ao menos em países de civil law, o caráter criativo do Poder Judiciário.

Ocorre que, se de um lado desvelou-se o necessário imbricamento ou cooriginariedade entre direito e moral por meio da consagração do princípio enquanto espécie de norma, em tese, oriundo de valores supra ou pré-positivos; velou-se o fato de que as regras - a despeito de positivadas e consagradoras de valores, diferenciando-se destes, por conterem um comando deontológico e não axiológico - se aplicam do mesmo modo que os princípios, afinal, ambos são projetos existenciais, meros textos que se transformam em norma a partir da aplicação.

A hipótese a ser sustentada neste trabalho é de que a diferença entre regras e princípios não é significativa, ponto de vista que vai de encontro às construções teórica de renomados juristas no âmbito nacional e internacional que compreendem existir tal distinção, seja a partir da diferença de grau e abstração, como assinalam Esser (1961), Larenz (2012) e Canotilho, (1997); seja de um prisma lógico-interpretativo, na visão de Dworkin (2007); ou a partir de um enfoque estrutural-argumentativo, na compreensão de Alexy (2017).

Assim, o objetivo deste trabalho é discutir algumas teses que advogam uma distinção fraca, caso da diferença centrada no grau de abstração e de generalidade; e outras centradas em distinções fortes, como as de Ronald Dworkin (2007) e Robert Alexy (2017).

Para cumprir tal tarefa foi adotada a metodologia jurídico-compreensiva e as técnicas da revisão bibliográfica e da análise de conteúdo. Tal caminho será trilhado nestes passos:

1) revisão bibliográfica e retrospectiva a respeito da normatividade dos princípios, tomada a partir do neopositivismo de Hans Kelsen (2009); 
2) breve descrição das contribuições dos autores que realizam tanto uma distinção fraca quanto forte entre os princípios e as regras jurídicas;

3) questionamento de alguns dos argumentos esboçados pelos defensores da teoria dos princípios, com suporte no pensamento do professor finlandês Aulis Aarnio (1997; 2012).

São esses os rumos trilhados até a conclusão pela indiferença entre princípios e regras.

\section{NORMATIVIDADE DOS PRINCÍPIOS: UM OLHAR RETROSPECTIVO}

A distinção entre princípios e regras tem como ponto de partida a tese da normatividade dos princípios.

Nesse sentido, cumpre, antes de discutir a diferença entre normas, refletir sobre alguns pressupostos históricos da compreensão dos princípios como normas jurídicas, para, então, esboçar e repensar as principais teorias da distinção entre regras e princípios. ${ }^{2}$

\subsection{OS PRINCÍPIOS DE KELSEN}

Hans Kelsen, com suas obras, em especial a Teoria Pura do Direito, distinguiu as normas jurídicas (fundadas na lógica no dever-ser, na imputação) das demais normas, objeto de outras ciências sociais (fundadas na lógica do ser, na causalidade, e voltada à verdade), de modo que trouxe dignidade teórica à ciência jurídica, ao circunscrever-lhe o objeto a partir do método que escolheu (KELSEN, 2009, p. 01).

Não custa lembrar que a principal reação à mixagem metodológica do positivismo sociológico veio das obras deste jurista austríaco radicado nos Estados Unidos ao nadar contra a corrente do modernismo jurídico e sua tentativa de retomar as discussões relativas à justiça a padrões de moralidade não só secundum legem ou praeter legem, então rejeitados pelo Positivismo Jurídico clássico (NEVES, 1995, p. 218).

Observa-se do neopositivismo lógico de Kelsen que, em termos estruturais, as normas são formadas por um juízo hipotético, contendo modais deônticos (proibido, obrigado,

\footnotetext{
${ }^{2}$ Este cuidado se justifica pela necessidade de fazer claro ao leitor as devidas distinções entre o que já se defendeu a respeito das regras e dos princípios e o que hora se advoga com o presente trabalho, sob pena de tomar o presente escrito por vinho novo em garrafa velha.
} 
permitido $^{3}$ ) em que se condiciona a aplicação de uma determinada sanção - consequência jurídica - à ocorrência de uma hipótese fática descrita, normalmente identificada pelo descumprimento de uma prestação (KELSEN, 2009, p. 01).

Essa associação da ideia de norma a um juízo hipotético condicional vem levando os mais apressados a crer que Kelsen restringe o seu conceito de norma ao que se convencionou contemporaneamente a chamar de regra, aquela proposição normativa que se aplica de forma automática e subsuntiva ante a ocorrência do suposto normativo, atribuindo-lhe, imediatamente, as consequências jurídicas previstas no dispositivo (ÁVILA, 2009, p.36-37).

Porém, observa-se que o jurista austríaco vem sendo mal compreendido, motivo pelo qual cabe discutir, brevemente, alguns aspectos da sua teoria que podem colaborar com outras observações a seu respeito, como pressuposto para dar seguimento ao breve esforço de reconstrução retrospectiva da importância dos princípios na Teoria do Direito.

Pois bem. Kelsen, no último capítulo da Teoria Pura do Direito explicita que

[...] todo o ato jurídico em que o Direito é aplicado, quer seja um ato de criação jurídica quer seja um ato de pura execução, é, em parte, determinado pelo Direito e, em parte, indeterminado. A indeterminação pode respeitar tanto ao fato (pressuposto) condicionante como à consequência condicionada (2009, p.246).

Mais à frente sustenta que:

[...] pela via da interpretação autêntica, quer dizer, da interpretação de uma norma pelo órgão jurídico que a tem de aplicar, não somente se realiza uma das possibilidades reveladas pela interpretação cognoscitiva da mesma norma, como também se pode produzir uma norma que se situe completamente fora da moldura que a norma a aplicar representa (2009, p.250).

Nesse sentido, observa-se que o conceito de norma para Kelsen não se identifica com a concepção geralmente aceita sobre regra enquanto espécie normativa.

Com efeito, de um lado, o intérprete não está limitado ao que fora previsto na moldura (hipótese e consequência; ou fato descrito e sanção prescrita) ao interpretar, sendo-lhe facultado suplantá-la, seja mediante a atribuição de outro sentido nela "não previsto" para

\footnotetext{
${ }^{3}$ Quanto à permissão ou faculdade Kelsen afirma que não interessa ao estudo teórico do Direito, afinal não há culminação de qualquer sanção àquele que não realiza o que lhe era facultado. Das suas palavras é possível colher o seguinte trecho: "A função da simples permissão negativa, que consiste em a ordem jurídica não proibir uma determinada conduta, já não nos interessa aqui, pois a permissão não é feita, nesse caso, através de uma norma positiva" (KELSEN, 2009, p. 40).
} 
regular um caso, ou da utilização de outra consequência para um fato previsto em dispositivo a priori aplicável.

De outro, a decisão faz do intérprete autêntico explicitamente um criador de direitos e, como o Direito se expressa pela via normativa, o seu produto é uma norma jurídica. Ou seja, para Kelsen, a norma de decisão não está dada previamente em um dispositivo e não decorre da produção legislativa, mas do ato decisório da autoridade competente para aplicar o Direito, cujo consequente e antecedente são objeto de sua criação (KELSEN, 2009, p.393).

Dessa maneira, é possível concluir, contrariamente ao que se defende comumente, que o conceito de norma, em Kelsen, não se identifica com o que contemporaneamente se convencionou chamar de regra. Isso porque, de um lado a norma de decisão não respeita em seu processo de formação a automação subsuntiva a que se atribui a aplicação das chamadas regras, posto que o interprete autêntico, em razão de ser a autoridade competente para decidir, é livre para construir as consequências jurídicas que regularão determinada conduta para além das hipóteses previstas na moldura delineada em um dispositivo. Nas palavras de Kelsen,

[o] tribunal é autorizado pela ordem jurídica a decidir o caso de acordo com o seu próprio arbítrio [...]. Isso significa que o tribunal é autorizado a criar para o caso concreto a norma de Direito substantivo que considera satisfatória, justa ou imparcial. O tribunal funciona como um legislador (2016, p. 211) (grifo nosso).

Nesse sentido, o produto de formação da norma de decisão, por ser decorrente da liberdade atribuída ao órgão julgador, não respeita necessariamente aos requisitos tidos como imprescindíveis para regular as condutas pelo método de aplicação atualmente atribuído às normas conhecidas como regras, já que "a norma individual criada pela decisão judicial irá sempre acrescentar algo novo" (KELSEN, 2016, p.211).

Embora não seja esta a compreensão corrente a respeito da relação entre a teoria da interpretação e a teoria da norma de Kelsen, os críticos do positivismo, precursores da teoria dos princípios, ao questionarem a concepção da norma kelseniana para propor balizas para o processo decisório, vão atribuir à regra uma dimensão automática e subsuntiva que não está presente na concepção normativa de Kelsen se observada a partir da sua teoria da interpretação. 
Como contraponto ao espantalho criado, irão resgatar do jusnaturalismo o princípio jurídico ora entendidos como os "diferentes fundamentos ideais fundamentais", os fundamentos da ordem jurídica, com função heurística ou unificadora para o sistema jurídico, conforme assinala Marcelo Neves (2014, p. 12). Dessa forma, retomam uma discussão que até meados do século XX se limitava à questão dos princípios gerais do direito, em franco retorno ao Direito Natural (MACHADO NETO, 1987) e que não fazia parte do ethos jurídico (LARENZ, 2012, p. 174).

No entanto, Kelsen não foi o único alvo de interpretações equivocadas dos críticos do positivismo. Em relação à aplicação do direito, a transição da teoria da norma para a teoria dos princípios atribuiu roupagem positivista à aplicação das normas na Alemanha nazista ao aproximá-lo das críticas já realizadas ao positivismo clássico de cariz exegético, assim como fizeram com o modelo kelseniano.

Ocorre que o modelo de aplicação do Direito Nazista está muito mais próximo das raízes jusnaturalistas defendidas pelos teóricos da dimensão principiológica do que das críticas que eles atribuíam ao modelo do nazismo ao identifica-lo com as teorias clássicas da norma com viés positivista.

Seguindo os rumos dessa crítica é que a dimensão dos princípios será observada logo a seguir.

\subsection{OS PRINCÍPIOS E O DIREITO NAZISTA}

Imbuídos do leitmotiv de defender a resolução dos problemas jurídicos com base em uma racionalidade moral enunciadora de critérios supralegais, as teorias dos juristas do direito nazista, a despeito da consagrada interpretação mundialmente propagada de que eram adeptos do positivismo jurídico, se fizeram majoritárias na Alemanha e legitimaram praeter legem os horrores característicos do totalitarismo genocida (KAUFMANN, 2004, p. 45).

Com efeito, não foi uma revolução legislativa que veio a forçar os juízes e demais operadores do direito de toda a Alemanha a aplicar o direito nazista, fundado na ideologia de limpeza étnica que o Führer pretendia impor ao mundo. O mesmo, porém, não se pode dizer em relação aos outros órgãos dos demais poderes da Alemanha nazista. 
A este respeito, o professor alemão Ulfrid Neumann, da Universidade de Frankfurt, aduz que

\begin{abstract}
[1]a transformación del Derecho operada de acuerdo com la ideologia nacionalsocialista no fue, em amplios ámbitos del ordenamento juridico, consecuencia de uma legislación revolucionaria, sino el solo resultado de uma complacente reinterpretación del Derecho vigente. La ideologia jurídica oficial del nacionalsocialismo estava más cerca ideológicamente del pensamento jusnaturalista que de uma concepcion positivista - a pesar del fuerte constraste material com los sistemas de Derecho natural tradicionales (NEUMANN, 1995, p. 435) (grifo nosso).
\end{abstract}

Nesse sentido, observa-se que da transição da República de Weimar para o Terceiro Reich, a imputação do direito para os judeus na Alemanha, à semelhança do tratamento dos direitos sociais, "eram direitos de hierarquia inferior aos direitos individuais clássicos e por isso os juízes negavam-lhes validade, decidindo como se eles não existissem" (RODRIGUEZ, 2016, p.88).

Ao revés do que reproduz o senso comum teórico dos juristas, as barbaridades cometidas pelo Estado Alemão Nazista não foram ancoradas na obediência serviçal à lei, elas não foram instrumentalizadas por intermédio da fonte primaz do direito positivo romanogermânico, não assistindo razão a quem afirma que se pautaram os nazistas nos postulados do positivismo jurídico (HASSEMER; KAUFMANN, 2012, p. 123-124).

A possibilidade de ultrapassar as cominações legais permitiu a aplicação irrefreada do direito nazista pelos juízes alinhados à ideologia nacional-socialista, o que, sob nenhum aspecto, permitia o descumprimento, pelos órgãos executores do Estado ou pela população, dos comandos daquela autoridade instituída de forma legítima, sob a argumentação de que se tratava ali do não-Direito.

É clássica a opinião de Kelsen a esse respeito:

[s] egundo o Direito dos Estados totalitários, o governo tem poder para encerrar em campos de concentração, forçar a quaisquer trabalhos e até matar os indivíduos de opinião, religião ou raça indesejável. Podemos condenar com a maior veemência tais medidas, mas o que não podemos é considerá-las como situando-se fora da ordem jurídica desses Estados [...] (2009, p. 28).

Uma evidência da incompreensão propalada por esta maneira de pensar acerca da relação entre o nazismo e o jusnaturalismo pode ser observada na postura teórica de Gustav 
Radbruch, jurista alemão defensor ferrenho do positivismo até 1946, que passou a atribuir aos estragos da guerra à ausência de justiça ante a preponderância da segurança jurídica.

Em razão de identificar o positivismo com a segurança jurídica, Radbruch compreendeu no pós-guerra que a aplicação pelo Estado nazista do direito válido era ilegítima. (LARENZ, 2012, p.132)

Dessa forma, defendeu a existência de leis que não são Direito, em razão de propalarem injustiças, e de Direitos acima das leis, que passou a identificar com os chamados Direito Humanos. Tratava-se, pois, da tentativa de impedir o renascimento da maior ditadura judicial já existente (MAUS, 2000, p. 198).

Segundo Ingeborg Maus, as Richterbriefe, as Cartas aos Juízes, são uma grande prova de como o direito nazista deveria ser aplicado pelos juízes na Alemanha. Nela continha a plena indicação de que os juízes seriam constituintes da nova elite nacional alemã, responsável por garantir a correta jurisprudência, tarefa que só poderia ser desempenhada por quem tivesse grande senso de responsabilidade e clareza interior, de modo que, segundo um jargão político da época, "juiz-rei do povo de Adolf Hitler deve libertar-se da escravidão da literalidade do direito positivo" (MAUS, 2000, p. 197).

Sobre esse ponto, Maus conclui que

[a]s Cartas aos Juízes também tinham em vista a elite judiciária, quando advertiam acerca de não se utilizar servilmente "das muletas da lei", sustentando também que o juiz era visto como "auxiliar direto da condução do Estado". Na verdade, revelavase aqui na forma de sua completa destruição a ligação entre legislação e independência da Justiça [...]. Esse processo foi direcionado mediante uma problemática moralização do conceito de direito. (2000, p.197) (grifo nosso).

Cumpre dizer que a observação a respeito da metodologia de aplicação do direito nazista, se fundada no positivismo ou no jusnaturalismo, faz-se necessária, porque o movimento pós-positivista ganhou espaço no pós-guerra, alegando a necessidade de reintrodução da moral como corretiva do direito, das pautas legais de valoração, no âmbito de sua aplicação, justamente o que apregoavam o modelo de aplicação do Direito do nazismo.

A esse respeito, é sintomático que um dos maiores defensores dos princípios durante a Segunda Guerra Mundial e no pós-guerra foi Karl Larenz que, ao lado de Carl Schmitt e Ernst Forsthoff, será considerado o mais importante jurista alemão simpatizante do nazismo e um dos precursores da Jurisprudência dos Valores - corrente defensora da teoria dos princípios. 


\subsection{OS PRINCÍPIOS DA JURISPRUDÊNCIA DOS VALORES}

À época do pós-guerra, o movimento que defendia a possibilidade de aplicação do direito com base em pautas supralegais de valoração, mediante a reintrodução da moral no direito, passou a ser chamado de Jurisprudência dos Valores, tendo como expoentes históricos Josef Esser, Claus-Wilhelm Canaris e Karl Larenz.

Conforme percebeu Larenz, a jurisprudência dos valores ganhou importância quando a atividade decisória passou a ser questionada no sentido de saber se

\footnotetext{
[...] existem valores e critérios de valoração extra ou supra legais a que [o juiz] possa e deva arrimar-se? [...] A passagem a uma jurisprudência da valoração só cobra, porém, o seu pleno sentido quando conexionada na maior parte dos autores com o reconhecimento de valores ou critérios de valoração <<supralegais〉> ou <<prépositivo $>$ que subjazem às normas legais e para cuja interpretação e complementação é legítimo lançar mão [...] (2012, p. 165-167).
}

Vale destacar que a Jurisprudência dos Valores vai ser responsável por resgatar da Jurisprudência dos Interesses a ponderação (LARENZ, 2012, p.77). Porém se antes estava centrada em bens e interesses, ora figura calcada nos valores, técnica que será desenvolvida, posteriormente, por Robert Alexy no âmbito de sua teoria dos direitos fundamentais e da argumentação jurídica (SIMIONI, 2014, 283).

Dessa forma, se de um lado é verdade que a normatividade dos princípios jurídicos ainda era indefinida até a metade do século passado, não é menos correto afirmar que sua normatividade passou a ser postulada como um verdadeiro resgate da razão prática no pósguerra. Trata-se de retorno que pode ser compreendido como fundante de um renovado pensamento jurídico ora centrado em diferente padrão de moralidade norteadora do processo de aplicação do direito, por óbvio distinto do conteúdo da ideologia nacional-socialista alemã, embora com formatação semelhante.

O passo seguinte que foi dado pelos teóricos do direito foi redimensionar a compreensão dos valores como pauta aferível pela razão, mediante a introdução de feição deontológica aos valores entendidos como finalidades ou estados ideais de coisas a serem 
perseguidos mediante determinados meios, objetivos cuja filosofia comumente tratava como objeto da esquecida axiologia jurídica.

Foi esse o contexto teórico que propiciou a percepção, inicialmente por Ronald Dworkin, e décadas após por Robert Alexy, da existência de normas que se diferenciavam das regras constantes nos dispositivos legais ou consagrados nos precedentes judiciais.

Tratava-se de comandos que, segundo estes autores, se diferenciavam quanto ao modo de aplicação, de resolução do conflito com outras normas e não só na estrutura formada por hipóteses condicionais com elevado grau de abstração e generalidade, conforme defendiam os tradicionais teóricos da jurisprudência da valoração e defensores da normatividade dos princípios como Esser, Larenz e Canaris (ÁVILA, 2009, p.45-51).

São esses os autores expoentes da teoria dos princípios cuja defesa da normatividade trouxe consigo a diferenciação entre princípios e regras. Os primeiros autores mencionados, Dworkin e Alexy, defendem teses fortes de distinção, ao tempo que os demais, sustentam a tese fraca de dissociação, segundo a classificação proposta por Aulis Aarnio (1997, p. 17-18).

A análise destas teorias sobre a distinção entre princípios e regras será o tema da investigação das linhas que seguem logo abaixo.

\section{A DISTINÇÃO ENTRE PRINCÍPIOS E REGRAS: PRINCIPAIS TEORIAS}

A discussão sobre a diferença entre regras e princípios ganha assento na teoria do direito, conforme relatado acima, com a reviravolta teórica proclamada pelos defensores do pós-positivismo jurídico, mediante a defesa de uma teoria dos princípios.

É a normatividade dos princípios e a sua importância como critério decisório, notadamente diante dos chamados casos difíceis, que notabilizaram a grandeza dessa corrente no âmbito da teoria do direito que pretende agregar, a um só tempo, as qualidades do jusnaturalismo e do positivismo jurídico.

Vejamos, sucintamente, algumas das teses dos referidos autores a respeito da questão.

\subsection{A DISTINÇÃO FRACA DA JURISPRUDÊNCIA DOS VALORES}


Defendida basicamente por Josef Esser, Karl Larenz e Claus-Wilhelm Canaris, a tese fraca da distinção entre regras e princípios é centrada no elevado grau de abstratividade e indeterminação atribuído aos princípios.

Inicialmente, convém tomar por base para a Jurisprudência dos Valores a conceituação a que chega Larenz a respeito do que são os princípios como o critério de referência para a sua distinção em relação às regras.

Segundo este autor,

[o]s <<princípios jurídicos〉> não são senão pautas gerais de valoração ou preferências valorativas em relação à ideia de Direito, que todavia não chegaram a condensar-se em regras jurídica imediatamente aplicáveis, mas que permitem apresentar $<<$ fundamentos jurídicos $>>$ delas [...] (2012, p. 316).

A partir desta enunciação é possível observar as duas características básicas dos princípios para a tese da distinção fraca das normas: grau de abstratividade e indeterminação.

Embora seja a abstratividade uma característica comum às regras jurídicas de uma forma geral, em termos estruturais, nos princípios, o seu suposto ou suporte fático abstrato abrange uma heterogeneidade de casos não abarcados pela regra, que pugna em sua hipótese fática por situações homogêneas para viabilizar a imputação da consequência jurídica que encerra a sua finalidade imediata.

Ademais, a distinção a que fazem referência os autores referidos, notadamente Esser e Larenz, está centrada também na diferença de grau de determinação entre princípios e regras.

Com efeito, as regras aplicam-se de forma direta e imediata aos casos previstos em seus preceitos, ao tempo que os princípios não se constituem como mandamentos por si mesmos, figurando tão somente como o critério para a justificação das pautas de valoração. Nos dizeres de Esser, os princípios seriam "[...] razões para regras concretizadas judicial ou legislativamente [...]" (1961, p. 66-67).

Também das palavras de Larenz é possível colher a compreensão da Jurisprudência dos Valores a respeito da diferença entre princípios e regras neste aspecto.

Ao contrário de um sistema de conceitos jurídicos gerais, um tal sistema de princípios jurídicos em que o <<princípio >>, ao invés do $\langle<$ conceito $>>$, deve ser entendido como uma pauta $<<$ aberta $>>$, carecida de concretização. Enquanto que o conceito (jurídico) contém a valoração só de modo indirecto, como que <<em 
cifra $>>,<<$ o princípio torna a valoração explícita $>$ e é por isso $<<$ mais apropriado para reflectir a unidade de valoração do Direito > [...] (2012, p. 235-236).

Já Canaris a compreende no seguinte sentido:

[...] os princípios << não regem sem excepções e podem entrar em oposição ou contradição; não apresentam uma pretensão de exclusividade - quer dizer, não poderiam ser formulados segundo um esquema "só quando...então"; desenvolvem o seu genuíno conteúdo de sentido apenas mediante um jogo concertado de recíproca integração e restrição; e carecem para a sua efectivação de concretização através de princípios e valorações particulares de conteúdo material autónomo. Não são $<<$ regras e, portanto, não são susceptíveis de aplicação imediata >>; necessita-se antes para tanto de um contínuo pôr em ação de <<novas valorações autônomas〉> [...] (2002, p. 75).

Dessa forma, pode-se concluir, em vias de síntese, que os princípios para a teoria fraca da dissociação, teriam grau elevado de abstração e dependeriam de uma concretização posterior, mediante mandamentos definitivos encontrados nas regras jurídicas.

Com efeito, observa-se que, para a Jurisprudência dos Valores, a importância dos valores - entendidos como princípios posteriormente - estava muito mais ligada à função do décimo segundo camelo da parábola árabe a que faz referência Luhmann do que propriamente por constituir um padrão regulatório à semelhança da norma - regra em nas distinções atuais próprio do Sistema do Direito (LUHMANN, 2004, p. 33-107).

Isso quer dizer que ao revés de refletir a estrutura operacional, símbolo generalizado de uma expectativa normativa a ser operada pelo Sistema do Direito no âmbito do Sistema da Sociedade, os valores, por figurarem como centros estabilizadores da legitimação racional do processo decisório no âmbito da fundamentação, gravitariam entre o Sistema do Direito e os demais Subsistemas Sociais, sem pertencer ao primeiro, contudo.

Dessa forma, assim como o juiz da parábola árabe emprestou um camelo para que os três herdeiros do beduíno falecido pudessem dividir com justeza os onze camelos que lhes foram testados por seu pai à razão de metade para o primeiro, 1/4 (um quarto) para o segundo e 1/6 (um sexto) para o terceiro, resultando da divisão a sobra de um camelo; no âmbito do direito, os valores consubstanciariam o camelo emprestado, esse elemento externo justificante, que permitiria a resolução do caso ${ }^{4}$.

\footnotetext{
${ }^{4}$ Questão curiosa seria se a herança fosse de 35 camelos e o testador dispusesse que a razão seria de metade para o primeiro filho, da terça parte para o segundo e da nona parte para o terceiro. Acaso o juiz emprestasse um só
} 
Entretanto, cabe refletir, nas trilhas de Luhmann, se o camelo deve ser devolvido e se ele pode ser devolvido pelo Sistema do Direito (LUHMANN, 2004, p. 06). ${ }^{5}$

Voltemos, porém, para os caminhos apontados pelos trilhos percorridos, no sentido de refletir tais questões a partir dos autores que estabelecem uma distinção forte entre os princípios e as regras.

\subsection{A DISTINÇÃO FORTE DE RONALD DWORKIN}

Sucessor da cátedra de Herbert Hart na Universidade de Oxford, Ronald Dworkin procurou, com sua teoria, superar o positivismo jurídico, sobretudo, por compreender o Direito como uma prática interpretativa, diretamente vinculada a uma perspectiva principiológica e ligada às convicções morais da comunidade (2007, p. 35-36).

A trajetória do pensamento de Dworkin é delineada pela crítica ferrenha ao positivismo jurídico, notadamente ao que denomina aguilhão semântico: redução da institucionalização do direito ao formato de textos (2007, p. 55-56).

A este respeito, o jurista inglês sintetizou em poucas palavras como os positivistas acabariam repetindo parte das concepções teóricas retrógradas dos nominalistas que “[...] pensam que quando falamos em direito, queremos dizer um conjunto de regras atemporais, estocadas em algum depósito conceitual à espera de que os juízes as descubram [...]” (2007, p. 25-26).

Como decorrência da ojeriza ao positivismo hartiano, o autor norte-americano radicado em Oxford elaborou seus mais conhecidos escritos, publicados em conjunto no livro "Levando os Direitos a Sério". Trata-se de obra formada por ensaios, dentre os quais os capítulos 2 e 3 são essenciais para o debate em questão. São eles: "modelo das regras I" e "modelo das regras II".

Para elucidar a diferença entre regras e princípios, Dworkin cita o caso Riggs vs. Palmer, em que um demandante-neto figurava como beneficiário do testamento de seu avô assassinado pelo postulante cuja herança lhe interessava. Em franca observância da

camelo, após a divisão sobrariam dois, ao que em uma versão modificada do conto os animais seriam vindicados como custas pelo trabalho realizado.

${ }^{5}$ Questões cujos limites deste artigo não permitem maiores digressões. 
integridade, a corte não acolheu a pretensão do demandante, inovando na ordem jurídica dos precedentes ao argumentar, em termos principiológicos - ou morais - que a ninguém seria dado beneficiar-se da própria torpeza (2007, p. 37).

Após enunciar outros casos, Dworkin afirma que Hart ignorava a importância dos princípios jurídicos como fontes do direito. Nesse sentido, segundo o jurista americano, as normas devem ser divididas em regras, princípios e políticas. Para ele, os princípios seriam

[...] um padrão que deve ser observado, não porque vá promover ou assegurar uma situação econômica, politica ou social considerada desejável, mas porque é uma exigência de justiça ou equidade ou alguma outra dimensão da moralidade [...] (2007, p. 36).

Enquanto que as políticas estariam relacionadas a

[...] aquele padrão que estabelece um objetivo a ser alcançado, em geral uma melhoria em algum aspecto econômico, político ou social da comunidade ainda que certos objetivos sejam negativos pelo fato de estipularem que algum estado atual deve ser protegido contra mudanças adversas [...] $(2007$, p. 36).

A partir destas definições é possível intuir as diferenças entre princípios e regras para Dworkin. Inicialmente, pode-se dizer que elas estão vinculadas à diferença no modo de aplicação das diversas espécies normativas, o que o autor denomina de diferença natureza lógica (2007, p. 39).

As regras aplicam-se de forma excludente, all or nothing, tudo ou nada. Ou seja, se uma regra estipula uma hipótese fática como condição para o implemento de uma consequência jurídica, a ocorrência do fato da vida que se amolde ao suporte fático implicará de logo a aplicação dos efeitos previstos na regra ou está será invalidada pelo sistema jurídico.

Em suas palavras, “As regras são aplicáveis à maneira tudo-ou-nada. Dados os fatos que uma regra estipula, então ou a regra é válida, e neste caso a resposta que ela fornece deve ser aceita, ou não é válida, e neste caso em nada contribui para a decisão [...]” (2007, p. 39).

Já os princípios são aplicados em uma dimensão de peso, de forma não excludente. Isso significa que "quando os princípios se intercruzam [...] aquele que vai resolver o conflito tem que levar em conta a força relativa de cada um" (2007, p. 42). 
Além dessas distinções, é possível indicar que, para Dworkin, os princípios são mais fracos em relação às regras, tendo em vista que comportam inúmeras exceções enquanto que as exceções das regras podem ser enumeradas:

\begin{abstract}
A regra pode ter exceções, mas, se tiver, será impreciso e incompleto simplesmente enunciar a regra, sem enumerar as exceções. Pelo menos em teoria, todas as exceções podem ser arroladas e, quanto mais o forem, mais completo será o enunciado da regra. Mas não é assim que funcionam os princípios [...] (2007, p. 40)
\end{abstract}

São estas algumas das linhas gerais das distinções teorizadas por Dworkin a respeito das regras e dos princípios. Vejamos o que escreveu Robert Alexy.

\title{
3.3 A DISTINÇÃO FORTE DE ROBERT ALEXY
}

No ano de 1978, veio a público a tese de doutoramento do jurista alemão Robert Alexy, defendida em 1976, sob o título "Teoria da Argumentação Jurídica”. Esta obra o fez conhecido no meio da Filosofia do Direito além da Saxônia, sobretudo ao ganhar o prêmio da Classe Filosófica-Histórica da Academia de Ciências de Göttingen.

Porém, foi um desdobramento do seu escrito anterior, fruto da habilitação para tornarse professor da Universidade de Göttingen em 1984, publicado em 1985, que o tornou mundialmente conhecido: a "Teoria dos Direitos Fundamentais". Nesse livro, Alexy passou a defender, dentre outras coisas, a existências de traços distintivos entre princípios e regras. No ano seguinte à publicação, foi ensinar na Universidade de Kiel, mais ao norte da Alemanha.

Observa-se que a produção teórica de Alexy é permeada pela necessidade de aproximar o direito e a filosofia, notadamente pela discussão travada em torno do discurso, se notabilizando por propor uma teoria discursiva do direito, inclusive o nome de um de seus livros traduzidos para português.

Em termos de argumentação jurídica, é nítida a forte ligação que o professor de Kiel tem com a teoria da ação comunicativa de Jürgen Habermas, especificamente no que tange ao entendimento do discurso jurídico como um caso especial do discurso prático geral. Com efeito, trata-se de orientação fundada na tradição neokantiana do direito que se expressa como

Rev. de Teorias do Direito e Realismo Jurídico | e-ISSN: 2525-9601 | Brasília | v. 3 | n. 1 | p. 104 - 126 | Jan/Jun. 2017. 
uma prática argumentativa racionalmente validada mediante a observação correta dos procedimentos racionais da argumentação, pensamento que Alexy vai procurar conciliar com as formas de argumentação de Perelman (SIMIONI, 2014, p. 233).

Quanto à teoria dos direitos fundamentais, Alexy objetiva aplicar sua teoria da argumentação jurídica, contextualizando-a junto ao movimento neoconstitucionalista que compreende nas constituições verdadeiros programas políticos dotados de exigências materiais a serem realizados. Assim, na esteira de Esser e Dworkin, acaba por elaborar a sua proposta de dissociação entre princípios e regras e propor a teoria da ponderação dos princípios como forma de solução para os casos difíceis (ALEXY, 2015, p.108).

Da análise da teoria dos direitos fundamentais, observa-se que Alexy propõe, conforme afirma textualmente, uma distinção estrutural entre regras e princípios. Trata-se, com efeito, de uma diferença qualitativa, cujo traço distintivo fundamental entre as duas espécies de normas é a estrutura dos direitos que são garantidos por elas (2017, p.43).

Para o autor alemão, os princípios são normas cujo mandamento requer realização

[...] na maior medida possível dentro das possibilidades jurídicas e fáticas existentes. Princípios são, por conseguinte, mandamentos de otimização, que são caracterizados por poderem ser satisfeitos em graus variados e pelo fato de que a medida devida de sua satisfação não depende somente das possibilidades fáticas, mas também das possibilidades jurídicas. O âmbito das possibilidades jurídicas é determinado pelos princípios e regras colidentes [...] (2017, p. 90).

Trata-se, com efeito, de normas cujas razões são prima facie, dependem de verificação posterior em face do caso concreto, diante de pautas valorativas mais fortes. Por esta razão, os princípios nunca asseguram direitos ou imputam deveres de forma definitiva como fazem as regras (ALEXY, 2017, p. 14).

Já as regras, Alexy afirma que contém critérios definitivos cuja satisfação ocorrerá ou não, mediante a verificação das exceções e a invalidação daquela que não for objeto de aplicação. Em sua concepção, as regras se caracterizam por serem sempre

[...] ou satisfeitas ou não satisfeitas. Se uma regra vale, então, deve se fazer exatamente aquilo que ela exige; nem mais, nem menos. Regras contêm, portanto, determinações no âmbito daquilo que é fática e juridicamente possível. Isso significa que a distinção entre regras e princípios é urna distinção qualitativa, e não urna distinção de grau. Toda norma é ou urna regra ou um princípio [...] (2017, p. 91). 
Nesse caso, assim como para Dworkin, Alexy compreende que as regras aplicam-se de modo automático, subsuntivo, no modelo all or nothing.

Porém, quanto aos princípios, diferentemente de Dworkin, Alexy entende se tratar de mandamentos de otimização, tendo em vista que sua satisfação pode ocorrer em graus variados; bem como sempre serão dependentes, conforme assinalado, não só das possibilidades fáticas, mas também das jurídicas, no que concerne às colisões entre princípios e regras $(2017$, p. 90)

\section{AARNIO E A INDIFERENÇA ENTRE PRINCÍPIOS E REGRAS}

O debate doutrinário sobre a diferença entre espécies normativa, conforme retrospectiva feita, foi enriquecido com as contribuições do jurista finlandês Aulis Aarnio, autor de estudos nas áreas de teoria do direito, filosofia jurídica e argumentação jurídica.

Embora reconhecido no exterior, o pensamento de Aarnio não tem tido a reflexão merecida no Brasil, conquanto as suas ideias se façam presentes direta ou indiretamente em ensaios de autores brasileiros. ${ }^{6}$

Nesse sentido, cabe tracejar, brevemente, algumas linhas sobre a sua trajetória acadêmica, relacionando ao contexto em que suas ideias sobre a diferenciação das espécies normativas em princípios e regras foram desenvolvidas.

Inicialmente, importa dizer que a formação jurídico-filosófica de Aulis Aarnio, assim como de seus contemporâneos finlandeses dos anos 50 e 70 do século XIX, em muito se deveu à Filosofia Analítica de cariz anglo-americano, notadamente centrada nos pensamentos de Georg Henrik von Wright e de Ludwig Wittgenstein.

Essa corrente teórica da filosofia da linguagem, cuja perspectiva de investigação esteve centrada em um modelo representacional, restrito à semântica e à sintaxe, foi bem desenvolvida com a obra "Tratado Lógico-Filosófico", objeto dos debates de Wittgenstein com Bertrand Russel, seu então professor no Trinity College.

Entretanto, foi com o livro "Investigações Filosóficas" que Wittgenstein alterou a rota da Filosofia Analítica ao destacar o valor da dimensão pragmática da linguagem,

\footnotetext{
${ }^{6}$ É o caso de Humberto Ávila (2009, p.33).
} 
influenciando todo o pensamento da filosofia da linguagem do século XX. É a partir dessa concepção de linguagem que Aulis Aarnio vai compreender que não existe nenhuma diferença entre regras e princípios do ponto de vista linguístico (AARNIO, 1997, p. 26).

Para sustentar esta concepção, o autor finlandês vai apontar cinco argumentos. O primeiro diz respeito à diferença entre a norma e a formulação da norma - distinção entre texto e norma - por meio da qual sustenta que todas as expressões linguísticas requerem interpretação, de modo que não é possível dividir as regras e os princípios em duas categorias separadas a priori, mas tão somente quando se levam em conta todos os fatores e se os interpreta (AARNIO, 1997, p. 26).

O segundo vetor argumentativo diz respeito ao grau de precisão ou de determinação que não é verificada tão-só nas regras, assim como a indeterminação não figura como característica exclusiva dos princípios (AARNIO, 1997, p.31).

Em um terceiro viés, quanto ao caráter (de)ontológico, Aarnio vai afirmar que as regras e os princípios são iguais, afinal "[...]do mesmo modo que no caso dos princípios, as regras têm uma natureza normativa (deôntica) e, tem isto presente, é irrelevante como se determine semanticamente o âmbito de aplicação da norma" (1997, p.27) (Tradução livre). Com isso, ele critica a exaltação da importância dos princípios que acaba por apequenar a relevância e a função das regras, afinal eles também estabelecem espécies precisas de comportamentos e não se limitam a explicitar valores.

Como quarto tópico de argumentação, Aarnio aponta que em situações de conflito normativo, observa-se que tanto as regras como os princípios têm plena capacidade de ceder em face da melhor regulação proposta pelas regras ou pelos princípios opostos ante à especificidade do caso, sem que tenham de ser declarados inválidos (AARNIO, 1997, p.28). Ou seja, as regras e os princípios podem ser igualmente ponderados e deles se podem extrair uma consequência jurídica, mediante a seleção de fatos, previstos em uma hipótese normativa ou consagrados pela prática jurisprudencial (AARNIO, 1997, p. 28-30).

Por fim, tanto as valorações contidas nas regras como nos princípios devem ser compreendidas como pautas racionais de justificação de uma determinada decisão. Dessa forma, se de um lado as regras podem fornecer razões de cariz definitivo e, eventualmente, prima facie; os princípios, à semelhança, não contribuem apenas com razões prefaciais, mas 
também definitivas, posto que "[e]m relação à aplicabilidade não há diferença essencial entre os princípios e as regras[....]" (AARNIO, 1997, p.31).

A definição do que seja princípio ou regra ocorre, por esse caminho, em momento posterior ao da interpretação, ou seja, se somente depois de decidido um problema jurídico, um observador poderá identificar se se trata de um princípio ou de uma regra (AARNIO, 1997, p. 31). Se de um texto há uma interpretação faz resultar princípios ou regras, a distinção é ornamental e não fornece parâmetros de fundamento razoável para justificar a sua escolha, afinal é o intérprete ou o leitor que determinará, sendo-lhe assegurado determinar qual espece normativa se trata no ato da interpretação. (AARNIO, 1997, p. 28-29).

Observa-se, com isso, que as teorias dos princípios deslocam a distinção regrasprincípios para momento posterior à interpretação, o que inviabiliza a consideração de que determinado dispositivo ou texto normativo é, ipso facto, constituinte de uma estrutura de regra ou de princípio e que se possa aplica-lo subsuntivamente ou não. Trata-se, pois, de dissociação que só é possível a posteriori.

Nesta linha de pensamento, se a definição da espécie normativa, princípio ou regra, não é um a priori à interpretação, mas a posteriori, não há como se determinar previamente qual a modalidade de aplicação, contrariando frontalmente as teses fortes da separação entre regras e princípios de Dworkin e Alexy. Afinal eles assumem como premissa que a definição do modo de aplicação normativa se dá em um processo prévio à interpretação ao dispor sobre o modo de aplicação das regras (tudo ou nada) e dos princípios (sopesamento/ponderação).

Dessa forma, a partir das premissas adotadas por Aarnio, é possível dizer que não subsiste diferença estrutural ou hermenêutica significativa entre princípios e regras para efeito da construção da decisão jurídica, sobretudo porque, seja no âmbito da estrutura, do modo de aplicação ou de colisão, se trata de distinção que assume como necessárias qualidades que são meramente contingentes. Conforme afirma Aarnio

[...] tanto las reglas como los principios expressan siempre uma norma del tipo o lo uno/o lo outro. Portanto, cuando se toma cuenta el resultado final, no es posible demonstrar uma diferencia entre estas categorias de normas [...] En resumo, la tesis de la demarcacion fuerte y tabién la debil son, pues, problemáticas en la medida tal que tenemos motivos para no olvidar que hay que tomar las reglas en serio. (1997, p. 33). 
Dessa forma, é possível concluir que, em termos estruturais e hermenêuticos, de metodologia da aplicação das normas, a distinção entre princípios e regras não se traduz como diferença significativa, senão a de um ornamento póstumo ao processo aplicativo.

\section{CONCLUSÃO}

O tempo se incumbiu de escancarar as insuficiências do paradigma que consagrou a restrição do jurídico ao legal e, com isso, a redução do direito à norma.

Com efeito, a reintrodução da teoria da justiça, de padrões éticos e dos cânones morais como balizas das teorias da decisão e da norma trouxeram como produto a ampliação do conceito de norma, que passou a abarcar não só a regra, mas, também, os princípios.

Esta alteração de paradigma no âmbito da compreensão da norma de direito, mais especificamente da teoria da norma jurídica, trouxe consequências importantes sobre muitos aspectos para toda a dogmática jurídica e, no âmbito da hermenêutica jurídica, acabou por evidenciar, ao menos em países de civil law, o caráter "criativo" do Poder Judiciário.

Ocorre que, se de um lado desvelou-se o necessário imbricamento ou cooriginariedade entre direito e moral por meio da consagração do princípio enquanto espécie de norma, em tese, oriundo de valores supra ou pré-positivos; velou-se o fato de que as regras possuem estrutura semelhante e se aplicam do mesmo modo que os princípios, afinal, ambos são projetos existenciais, meros textos que se transformam em norma a partir da aplicação e ambas consagram valores e possuem estrutura deontológica.

Com isso, afirma-se que o fato de se invocar uma regra e não um princípio, em um caso, ou vice-versa, em nada esclarece, ipso facto, o procedimento ou o raciocínio de quem o decide, este sim o mais importante para justificar uma decisão.

É nessa quadra que surge a importância retomar a semântica do termo princípio, que no latim principium remonta àquilo que serve de base para algo. Apesar do termo se referir ao início, ao a priori, prima facie, a construção da normatividade dos princípios vem sendo acompanhada da compreensão de que ele, assim como a regra, na condição de norma jurídica (e não como texto normativo) é o resultado de uma determinada interpretação. Ou seja, se uma norma jurídica decorre da interpretação de um fato, previsto no âmbito normativo, objeto de regulação por um texto que vem a decidir um determinado conflito, tem-se, por 
consequência, que uma eventual distinção entre regra e princípio só é possível a posteriori, nunca antes de sua interpretação-aplicação do dispositivo jurídico.

Dessa forma, se uma dita regra contiver um comando que, no caso, seja mais relevante que um princípio, ou o contrário, o raciocínio que o jurista-intérprete utilizará para fundamentar a sua compreensão-decisão não levará em conta uma suposta categoria prévia a que pertença o texto normativo, se regra ou princípio, mas, sim, a sua importância para resolver o conflito jurídico. Isso porque de nada lhe será útil saber a natureza a priori de determinada norma, afinal é o seu sentido que interessa na aplicação e não uma suposta diferenciação dogmática ornamental que em nada alterará o procedimento de feição normativo-prescritiva inerente ao processo compreensivo ou de justificação do ato decisório.

Assim, é possível concluir que, conquanto historicamente tenha se consagrado a importância da reintrodução da discussão apagada do panorama teórico do direito sobre a necessidade de reaproximar o direito da racionalidade prática inerente às teorias da justiça $\mathrm{e}$ dos padrões de moralidades supralegais subjacentes a um determinado ordenamento jurídico, a distinção analítica entre regras e princípios não se sustenta significativamente, quedando como mero ornamento estrutural do observador analítico.

\section{REFERÊNCIAS}

AARNIO, Aulis. Las reglas en serio. In: Aarnio, Aulis; Garzón Valdés, Ernesto; Uusitalo, Jyrki (Comp.). La normatividad del derecho. Barcelona: Gedisa, 1997.

Essays on the doctrinal study of law. Nova York: Springer, 2011.

The rational as reasonble. A treatise on legal justification, Dordrecht: Reidel, 2012.

ALEXY, Robert. Teoria dos direitos fundamentais. $2^{\text {a }}$ ed. $5^{\text {a }}$ tir., São Paulo: Malheiros Editores, 2017.

Constitucionalismo discursivo. 4. ed. Porto Alegre: Livraria do Advogado, 2015.

ÁVILA, Humberto. Teoria dos princípios: da definição à aplicação dos princípios jurídicos. 9 ed. São Paulo: Malheiros, 2009.

CRUZ, Álvaro Ricardo Souza. Regras e Princípios: por uma distinção normoteorética. Revista da Faculdade de Direito UFPR, Curitiba, PR, v. 45, p. 37-73, 2006. 
DWORKIN, Ronald. Levando os direitos a sério. 2. ed. São Paulo: Martins Fontes, 2007.

O império do direito. 3. ed. São Paulo: Martins Fontes, 2014.

HART, H. L. A., O conceito de direito. São Paulo: Martins Fontes, 2009.

KELSEN, Hans. Teoria Pura do Direito. São Paulo: Martins fontes, 2009.

Teoria Geral do Direito e do Estado. 4ª . ed. São Paulo: Martins Fontes, 2016.

KAUFMANN, Arthur. HASSEMER; Winfried. Introdução à filosofia do direito e à teoria do direito contemporâneas. Lisboa: Fundação Calouste Gulbenkian, 2002.

Filosofia do direito. Lisboa: Fundação Calouste Gulbenkian, 2004.

LARENZ, Karl. Metodologia da Ciência do Direito. 6.ed. Lisboa: Fundação Calouste Gulbenkian, 2012.

LOPES, J. R. L.. Juízo jurídico e a falsa solução dos princípios e regras. Revista de Informação Legislativa, Brasília, DF, v. 40, n.160, p. 49-64, 2003.

LUHMANN, Niklas. A restituição do décimo segundo camelo: do sentido de uma análise sociológica do direito. In LOPES JR., Dalmir; ARNAUD, André-Jean. Niklas Luhmann: do sistema social à sociologia jurídica. Rio de Janeiro: Editora Lumen Juris, p. 33-107, 2004.

MACHADO NETO, Anônio Luis. Sociologia Jurídica. 6. ed., São Paulo: Saraiva, 1987.

MAUS, Ingeborg. Judiciário como Superego da Sociedade: o papel da atividade jurisprudencial na "sociedade órfã". Novos Estudos CEBRAP, n” 58, 2000.

NEVES, Antônio Castanheira. Metodologia jurídica: problemas fundamentais. Coimbra: Coimbra Editora, 1995.

NEUMANN, Ulfrid. Positivismo jurídico, realismo jurídico y moralismo jurídico en el debate sobre "delincuencia estatal" en la anterior RDA. Doxa: Cuadernos de filosofía del derecho, n. 17-18, p. 435-444, 1995.

PINTO NEVES, Marcelo da Costa. Entre Hidra e Hércules: princípios e regras constitucionais. 2. ed. São Paulo: Martins Fontes, 2014.

RODRIGUEZ, José Rodrigo. Sociedade contra o Estado - duas ondas de democratização radical no Brasil (1988 e 2013): uma interpretação à luz de Franz Neumann. Constituição, sistemas sociais e hermenêutica: anuário do programa de pós-graduação da UNISINOS (orgs.) ROCHA, Leonel Severo [et. al]: Livraria do Advogado, 2016. 
SILVA, Virgílio Afonso da. Direitos Fundamentais: conteúdo essência, restrições e eficácia. 2. Ed. São Paulo: Malheiros, 2010.

Princípios e regras: mitos e equívocos acerca de uma distinção. Revista LatinoAmericana de Estudos Constitucionais, n. 1, p. 607-630, jan./jul. 2003.

SIMIONI, Rafael Lazzaroto. Curso de Hermenêutica Jurídica Contemporânea. Do positivismo Clássico ao Pós-positivismo jurídico. Curitiba: Juruá, 2014. 